\title{
Unilateral Common Iliac Artery Ostial Lesion Stenting versus Kissing Stenting
}

Mohammed said Mohammed, ${ }^{1}$ MSc, Abd El Fatah Ali Ismail, ${ }^{1}$ MD, Mohamed Hamza Hamed, ${ }^{1}$ MD.

* Corresponding Author:

Mohammed said Mohammed dmsaid89@gmail.com

Received for publication April 2, 2021; Accepted May 31, 2021; Published online May 6, 2021, 2021.

Copyright The Authors
published by Al-Azhar
University, Faculty of Medicine,
Cairo, Egypt. Users have the
right to read, download, copy,
distribute, print, search, or link
to the full texts of articles under
the following conditions:
Creative Commons Attribution-
Share Alike 4.0 International
Public License (CC BY-SA 4.0).
doi: 10.21608/aimj.2021.68012.1449.
${ }^{1}$ Vascular Surgery Department,
Faculty of Medicine, Al-Azhar
University.

University.

\begin{abstract}
Background: Iliac arteries are a common sites of occlusive atherosclerotic disease that is responsible for symptomatic arterial insufficiency of lower extremities and as atherosclerosis is a systemic disease, iliac diseases frequently have coexistent disease below inguinal ligament.

Aim of the study: This study aimed to assess using of unilateral Common iliac artery stent versus kissing stent as regard clinical and technical success in unilateral ostial common iliac artery lesions.

Patients and Methods: From December 2018 to December 2020 in AlAzhar University Hospital and Military Hospitals in Cairo, we assigned 20 patients with unilateral common iliac artery ostial lesion to undergo either unilateral stent or kissing stent; in two equal groups. Patients were followed up clinical, technical success and complications.

Results: Regarding co morbidities, $80 \%$ were smokers, $40 \%$ were diabetic, $40 \%$ had hypertension (HTN), and $40 \%$ had ischemic heart disease (IHD). Regarding complication, 15\% had small groin heamatoma, $1 \%$ had distal emboli, 5\% had arterial dissection and 5\% had contrast induced nephropathy.

Conclusion: No significant difference between unilateral and kissing technique regarding clinical, technical success and complications. The unilateral stent is safe and effective as kissing stents in the treatment of unilateral common iliac artery ostial lesions as regarding to high technical, clinical success and patient clinical improvement.
\end{abstract}

Keywords: Kissing stent; iliac artery; ostial lesion; angioplasty.

Disclosure: The authors have no financial interest to declare in relation to the content of this article. The Article Processing Charge was paid for by the authors.

Authorship: All authors have a substantial contribution to the article.

\section{INTRODUCTION}

Iliac arteries are most common sites of the occlusive atherosclerotic disease that is responsible for symptomatic arterial insufficiency of lower extremities. ${ }^{1} \quad$ Iliac atherosclerosis may be asymptomatic or presented by acute ischemia, intermittent claudication, critical limb ischemia (CLI). ${ }^{2}$ The advancing role of the minimal invasive vascular intervention is affected by multiple factors, including imaging technology advancement, reduced morbidity \& mortality rate in endovascular interventions, as well as faster convalescence following percutaneous therapy when compared to surgery. ${ }^{3}$ Due to low morbidity and mortality rates in iliac angioplasty, become a option to bypass surgery for treatment of short iliac occlusive lesions. ${ }^{4}$ The Trans Atlantic Inter-Society Consensus (TASC) has published a consensus document with recommendation for treatment of peripheral arterial diseases. ${ }^{5}$ The TASC classify iliac artery lesions according to complexity to Type A, B, C\& D lesions. Endovascular therapy is the best choice for type A lesions and surgery is preferred for type D lesions. ${ }^{5}$ Lesions at the orifice of the common iliac artery at aortic bifurcation have another considerations as intervention on one iliac may lead to affect of origin of other iliac by moving of eccentric plaque so using of the kissing stent technique protect the other iliac origin. ${ }^{6}$

This work aimed to assess using of unilateral common iliac artery stent versus kissing stent as regard clinical and technical success in unilateral ostial common iliac artery lesions.

\section{PATIENTS AND METHODS}

In this prospective study from December 2018 to December 2020 in Al-Azhar University Hospital and Military Hospitals in Cairo, we assigned 20 patients with unilateral ostial iliac lesion underwent either unilateral stent or kissing stenting; 10 patients in each group. Patients were followed for type of technical, clinical success and complications. 
Inclusion criteria: Patient (male \&female) with, unilateral ostial iliac artery lesion, disabling claudication pain not respond to medical treatment or have tissue loss or gangrene.

Exclusion criteria: Patients with short life expectancy or terminal patient, Previous stent implantation in the target vessel or Known hypersensitivity to contrast material or Renal function impairment or Patient with an abdominal aortic or iliac aneurysm.

For every patient, the following were required: Medical history and full physical examination, laboratory tests (complete blood count, complete coagulation profile, and kidney function test), and computed angiography .

\section{RESULTS}

\section{Statistical Analysis:}

Data entry, process with statistically analysis was carried out by MedCalc ver. 18.2.1 (MedCalc, Ostend, Belgium). Significant tests (MannWhitney's, Chi square tests, logistic regression analysis and Spearman's correlation) were used. Data presented and analysis was done according to the type of data (parametric and non-parametric) obtained for each variable. P-values less than 0.05 (5\%) was considered to be statistically significant.

\section{Discriptive statistics:}

Mean, Standard deviation ( \pm SD) and range numerical data, while Median and Inter-quartile range (IQR) non-parametric data. Frequency and percentage of non-numerical data.

\section{Analytical statistics:}

Mann-Whitney's Test (U test) used to evaluate the statistical significance of the difference of a nonparametric variable between two study groups. ChiSquare test was used to assess the relationship between two qualitative variables. Correlation analysis (using Spearman's method): To assess the strength of association between two quant (itative variables. The correlation coefficient denoted symbolically " $r$ " defines the strength and direction of the linear relationship between two variables. Logistic regression: useful in the prediction of the presence or absence of an outcome based on a set of independent variables.
Table 1 shows that there is 16 (80\%) males, 4 (20\%) females, $9(45 \%)<60$ years old, $11(55 \%)>60$ years old, the mean of age 61.35 ( $\pm 6.57 \mathrm{SD})$.

Regarding comorbidities, Table 2 shows that there is 16 (80\%) had HTN, 7 (35\%) had hyperlipidemia, 8 (40\%) had DM and 8 (40\%) had IHD.

Table 3 shows that there is 4 (20\%) non-smokers and $16(80 \%)$ smokers.

Table 4 shows that ipsilateral and contralateral femoral access used in 16 (80\%) of cases and left brachial access and contralateral femoral access used in $4(20 \%)$.

\begin{tabular}{|l|l|l|}
\hline & No. & $\%$ \\
\hline Gender & & \\
\hline Male & 16 & 80.0 \\
\hline Female & 4 & 20.0 \\
\hline Age (years) & & \\
\hline$<60$ & 9 & 45.0 \\
\hline$>60$ & 11 & 55.0 \\
\hline Min. - Max. & $51.0-77.0$ \\
\hline Mean \pm SD. & \multicolumn{2}{|l|}{$61.35 \pm 6.57$} \\
\hline Median (IQR) & \multicolumn{2}{|l|}{$61.0(57.0-64.0)$} \\
\hline
\end{tabular}

Table 1: Distribution according to demographic data $(\mathrm{n}=20)$ (IQR: Inter quartile range).

\begin{tabular}{|l|l|l|}
\hline Co-morbidity & No. & $\%$ \\
\hline HTN & 16 & 80.0 \\
\hline Hyperlipidemia & 7 & 35.0 \\
\hline DM & 8 & 40.0 \\
\hline IHD & 8 & 40.0 \\
\hline
\end{tabular}

Table 2: Distribution according to co-morbidity ( $\mathrm{n}=$ 20).

\begin{tabular}{|l|l|l|}
\hline Special Habits & No. & $\%$ \\
\hline No smoker & 4 & 20.0 \\
\hline Smoker & 16 & 80.0 \\
\hline
\end{tabular}

Table 3: Distribution according to special habits $(\mathrm{n}=$ 20).

\begin{tabular}{|l|l|l|}
\hline Access & No. & $\%$ \\
\hline $\begin{array}{l}\text { Ipsilateral and contralateral } \\
\text { femoral access }\end{array}$ & 16 & 80.0 \\
\hline $\begin{array}{l}\text { Left brachial access and } \\
\text { contralateral femoral } \\
\text { access }\end{array}$ & 4 & 20.0 \\
\hline
\end{tabular}

Table 4: Distribution according to access $(n=20)$.

\begin{tabular}{|l|l|l|l|c|}
\hline \multicolumn{1}{|c|}{ ABPI } & \multicolumn{1}{|c|}{$\begin{array}{c}\text { Pre-operative } \\
(\mathrm{n}=20)\end{array}$} & $\begin{array}{c}\text { Post-operative } \\
(\mathrm{n}=20)\end{array}$ & $\mathrm{p}$ \\
\cline { 1 - 3 } Min. - Max. & $0.30-0.48$ & $0.78-0.93$ & \multirow{2}{*}{$36.822^{*}$} & $<0.001^{*}$ \\
\cline { 1 - 3 } \pm Mean SD. & $0.38 \pm 0.06$ & $0.88 \pm 0.04$ & & \\
\cline { 1 - 3 } Median (IQR) & $0.39(0.32-0.43)$ & $0.89(0.86-0.91)$ & & \\
\hline
\end{tabular}

Table 5: Comparison between the pre and post-operative ABPI: 


\begin{tabular}{|c|c|c|}
\hline Complications & No. & $\%$ \\
\hline Groin heamatoma & & \\
\hline No & 17 & 85.0 \\
\hline Yes (small hematoma manged conservative) & 3 & 15.0 \\
\hline Retroperitonial heamatoma & 0 & 0.0 \\
\hline Stent mal position & 0 & 0.0 \\
\hline $\begin{array}{l}\text { Distal embolization } \\
\text { No }\end{array}$ & 19 & 95.0 \\
\hline $\begin{array}{l}\text { Yes represented by blue toe syndrome treated by SC } \\
\text { anticoagulant \&getting better after } 2 \text { week }\end{array}$ & 1 & 5.0 \\
\hline Acute Thrombosis & 0 & 0.0 \\
\hline perforation / rupture & 0 & 0.0 \\
\hline Arterial dissection & & \\
\hline No & 19 & 95.0 \\
\hline Yes (common iliac artery) treated by stent & 1 & 5.0 \\
\hline Stent infection & 0 & 0.0 \\
\hline Contrast induced nephropathy CIN & & \\
\hline No & 19 & 95.0 \\
\hline $\begin{array}{l}\text { Yes (s.cr: } 2.3 \text { post-operative \&treated conservative return to } \\
\text { normal level within } 3 \text { weeks }\end{array}$ & 1 & 5.0 \\
\hline
\end{tabular}

Table 6: Distribution according to complications $(n=20)$

\begin{tabular}{|l|l|l|}
\hline Technical success & No. & $\%$ \\
\hline $\begin{array}{l}\text { Angiographic appearance } \\
\begin{array}{l}\text { Complete angiography without residual stenosis denote } \\
\text { technical success }\end{array}\end{array}$ & 20 & 100.0 \\
\hline $\begin{array}{l}\text { Pressure gradient by duplex } \\
\text { Less } 10 \mathrm{~mm} \mathrm{Hg}\end{array}$ & 20 & 100.0 \\
\hline
\end{tabular}

Table 7: Distribution according to technical success $(\mathrm{n}=20)$

\begin{tabular}{|c|c|c|c|c|c|c|}
\hline \multirow{3}{*}{ Follow up by duplex } & \multicolumn{4}{|c|}{ Technique } & \multirow{3}{*}{$\chi^{2}$} & \multirow{3}{*}{${ }^{F E} p$} \\
\hline & \multicolumn{2}{|c|}{$\begin{array}{l}\text { Unilateral } \\
(\mathrm{n}=10)\end{array}$} & \multicolumn{2}{|c|}{$\begin{array}{l}\text { Kissing } \\
(\mathrm{n}=10)\end{array}$} & & \\
\hline & No. & $\%$ & No. & $\%$ & & \\
\hline 6 month & & & & & & \\
\hline Patent stent with good inflow & 9 & 90.0 & 10 & 100.0 & 1.053 & 1.000 \\
\hline $\begin{array}{l}\text { Claudication pain again at } 100 \text { meter significant } \\
\text { stenosis occur treated by ballon expandable stent }\end{array}$ & 1 & 10.0 & 0 & 0.0 & & \\
\hline 1 year & & & & & & \\
\hline Patent stent with good inflow & 9 & 90.0 & 10 & 100.0 & 1.053 & 1.000 \\
\hline Chronic renal failure \& died & 1 & 10.0 & 0 & 0.0 & & \\
\hline
\end{tabular}

Table 8: Relation between technique and follow up by duplex $(n=20)$

\section{DISCUSSION}

Endovascular intervention is now the preferred option for treating obstructive atherosclerotic diseases of the iliac arteries due to the fast development of endovascular devices and increase of practitioners experience. ${ }^{7}$ Unilateral CIA ostium lesions have been treated with kissing stents to avoid plaque shifting and embolization to the contralateral iliac artery. However, the kissing stents technique requires more devices, bilateral femoral artery access. ${ }^{8}$ The aim of this work to assess using of unilateral CIA stent vs kissing stent as regard clinical and technical success. In our study there is $16(80 \%)$ males, 4 (20\%) females, $9(45 \%)<60$ years old, 11 (55\%) $>60$ years old, the mean of age $61.35( \pm 6.57$ $\mathrm{SD})$.
In a study showed that the patients were a mean age was 68 years (range, $37-83$ years). ${ }^{9}$ He showed that $86.3 \%$ male in his study. In our study there is 16 (80\%) had HTN, 7 (35\%) had hyperlipidemia, 8 (40\%) had DM and 8 (40\%) had IHD. In a study showed that there were $37 \%$ of his patients suffer from hypertension, 21\% with Hyperlipidemia, 8\% with diabetes. ${ }^{9}$ In our study that there is 4 (20\%) nonsmokers and $16(80 \%)$ smokers. In a study showed that there were $58 \%$ smokers, $33 \%$ ex-smoker. ${ }^{10}$ In our study there is 1 (5\%) had Gangrenous patch at tip of left big toe (tissue loss) , disabling claudicating pain hip \& buttocks, 15 (75\%) had Disabling claudicating pain hip \& buttocks, 1 (5\%) had Gangrenous skin of dorsum of forefoot of rt foot and 2 (10\%) had rest pain, 1 (5\%) had Gangrenous patch of rt heel. In a study reported that following procedure, the ABI significantly increased in all the patients (pre $A B I$ vs. post $A B I$ mean values were 0.4 
vs. $0.82 ; \mathrm{p}=2.20 \times 10-16) .{ }^{11}$ Our study shows that according to technical success there is $20(100 \%)$ had complete angiography without residual stenosis denote technical success and 20 (100\%) had pressure gradient by duplex less than $10 \mathrm{mmHg}$. In a study showed that the procedure was technically successful in $100 \%$ of patients. ${ }^{12}$ Our study shows that according to complication there is $3(15 \%)$ had groin heamatoma, 1 (5\%) had distal embolization, 1 (5\%) had arterial dissection, 1 (5\%) had contrast induced nephropathy CIN. In study showed that a hematoma at the puncture site occurred in 15 (7.1\%) of 212 groins, but none required surgical repair. ${ }^{13}$

Our study shows that there no significant difference between Unilateral and kissing technique as regards sex and age. In a study showed that Baseline clinical characteristics (including age and sex) has not insignificant different between the both group. ${ }^{9}$ In a study using kissing stent, Duplex imaging diagnosed significant restenosis in 15 (14.8\%) of 101 patients and restenosis in 4 (4\%), with recurrent symptoms in 17 (89.5\%) of these 19 patients. ${ }^{13}$ Our study shows that there no significant difference between Unilateral and kissing technique as regards access (Ipsilateral and contralateral femoral access \& Left brachial access and contralateral femoral access). A study by Suh, $\mathrm{Y}$ et al reported that there no significant difference between single-stent and kissing technique as regards access(unilateral femoral, Bilateral femoral, Brachial artery). ${ }^{9}$ Our study shows that there no significant difference between Unilateral and kissing techniques as regards ABPI (pre-operative and post-operative). A study by Suh, Y et al reported that Post procedural ABPI in the both limb did not differ between the two groups. ${ }^{9}$ The study reported that there no significant difference between single-stent and kissing technique as regards ABPI (ipsilateral or contralateral). ${ }^{9}$ Our study shows that there no significant difference between Unilateral and kissing techniques as regards complication. Another study reported that major complications between the two groups were not significant. ${ }^{9}$

\section{CONCLUSION}

In our study, the unilateral stent technique is safe and effective like kissing stent technique in unilateral common iliac artery ostial lesions treatment as regarding to high technical, clinical success and patient clinical improvement.

\section{REFERENCES}

1. Alan TN, Mark B, Landon CY, et al. Timing of Elective Repeat Cesarean Delivery at Term and Neonatal Outcomes. $N$ Engl J Med. 2009; 360:111-20.

2. Brewster DC, LaSalle AJ and Robison JG. Direct reconstruction for aortoiliac occlusive disease. In r. b. rutherford, vascular surgery. (2019; 6th ed., pp. 1106-36). Phliadelphia: Elsevier Saunders

3. Gaines PA., Goode SD and Cleveland TJ. Iliac occlusive disease (indication for treatment, technical aspects, current results, and troubleshhoting complications). In M. M. Thompson, R. A. Morgan, J. S. Matsumura, M. Sapoval, \& I. M. Loftus, Endovascular Intervention for Vascular Disease Principles and Practice ( 2014; 9-19). New York,: Informa Healthcare USA, Inc.

4. Lumsden AB, Peter Lin PH, Bush RL, et al. Endovascular Therapy Principles of Peripheral Interventions. London: Blackwell Publishing. 2011;19(2): 122-6..

5. Adam DJ and Bradbury, AW. Recent Trials for Chronic Lower Limb Ischemia. In M.M. Thompson, et al. Endovascular Intervention for Vascular Disease Principles and Practice (2013; 79-85). New York,: Informa Healthcare.

6. Leville CD, Kashyap VS, Clair DG, et al. Endovascular management of iliac artery occlusions: extending treatment to TransAtlantic Inter-Society Consensus class $C$ and D patients. $J$ Vasc Surg. 2016; 43: 32-9.

7. Peden E, Bush RL and Lumsden AB. Aortoiliac occlusive disease. In A. B. Lumsden, P.H. Lin, R.L. Bush, \& C. Chen, Endovascular therapy principle of peripheral intervention (2010; 170184). Massachusetts: Blackwell Publishing.

8. Piffaretti G, Fargion AT, Dorigo W, et al. Outcomes From the Multicenter Italian Registry on Primary Endovascular Treatment of Aortoiliac Occlusive Disease. Journal of Endovascular Therapy. 2019; 26(5), 623-32.

9. Al-Sibbai AAZ, Santervás LAC, Marcos FÁ, et al. Midterm results of endovascular treatment for complete iliac axis occlusions using covered stents. Annals of Vascular Surgery.2020; 63, 241249.

10. Suh, Y., Ko, Y.-G., Shin, D.-H., Kim, J.-S., Kim, B.-K., Choi, D., ... Jang, Y. (2015). Outcomes of the single-stent versus kissing-stents technique in asymmetric complex aortoiliac bifurcation lesions. Journal of Vascular Surgery. 2015; 62(1), 68-74.

11. Faheez Mohamed B, Sarkar G, Timmons A, et al. Outcome of "Kissing Stents" for Aortoiliac Atherosclerotic Disease, Including the Effect on the Non-diseased Contralateral Iliac Limb. Cardiovascular and interventional radiology. 2002; 25(6), 472-5.

12. Cvetic V, Sagic D, Koncar I, et al. Endovascular treatment of different types of iliac occlusionsResults from an observational study. PLOS ONE. 2019; 14(10), 0222893.

13. Maitrias P, Deltombe G, Molin V, et al. Iliofemoral endarterectomy associated with systematic iliac stent grafting for the treatment of severe iliofemoral occlusive disease. Journal of Vascular Surgery. 2017; 65(2), 406-13.

14. Haulon S, Mounier-Véhier C, Gaxotte V, et al. Percutaneous Reconstruction of the Aortoiliac Bifurcation with the "Kissing Stents" Technique: Long-term Follow-up in 106 Patients. Journal of Endovascular Therapy. 2002; 9(3), 363-8. 